\title{
Determination of gaseous and particulate carbonyls (glycolaldehyde, hydroxyacetone, glyoxal, methylglyoxal, nonanal and decanal) in the atmosphere at Mt. Tai
}

\author{
K. Kawamura ${ }^{1}$, K. Okuzawa ${ }^{1,2}$, S. G. Aggarwal ${ }^{1, *}$, H. Irie ${ }^{3,4}$, Y. Kanaya ${ }^{3}$, and Z. Wang ${ }^{5}$ \\ ${ }^{1}$ Institute of Low Temperature Science, Hokkaido University, Sapporo 060-0819, Japan \\ ${ }^{2}$ Graduate School of Environmental Science, Hokkaido University, Sapporo, Hokkaido, 060-0810, Japan \\ ${ }^{3}$ Research Institute for Global Change, Japan Agency for Marine-Earth Science and Technology, Kanagawa 236-0001, Japan \\ ${ }^{4}$ Center for Environmental Remote Sensing, Chiba University, Chiba 263-8522, Japan \\ ${ }^{5}$ Institute of Atmospheric Physics, Chinese Academy of Sciences, Beijing 100029, China \\ *now at: CSIR-National Physical Laboratory, New Delhi 110012, India
}

Correspondence to: K. Kawamura (kawamura@ lowtem.hokudai.ac.jp)

Received: 10 January 2013 - Published in Atmos. Chem. Phys. Discuss.: 25 January 2013

Revised: 2 May 2013 - Accepted: 2 May 2013 - Published: 28 May 2013

\begin{abstract}
Gaseous and particulate semi-volatile carbonyl compounds were determined every three hours in the atmosphere of Mount Tai (elevation, $1534 \mathrm{~m}$ ) in the North China Plain during 2-5, 23-24 and 25 June 2006 under clear sky conditions. Using a two-step filter cartridge in a series, particulate carbonyls were first collected on a quartz filter and then gaseous carbonyls were collected on a quartz filter impregnated with O-benzylhydroxylamine (BHA). After the two-step derivatization with BHA and N,O-Bis(trimethylsilyl)trifluoroacetamide (BSTFA), carbonyl derivatives were measured using a gas chromatography. The gaseous concentrations were obtained as follow: glycolaldehyde (range $0-826 \mathrm{ng} \mathrm{m}^{-3}$, average $\left.303 \mathrm{ng} \mathrm{m}^{-3}\right)$, hydroxyacetone $\left(0-579 \mathrm{ng} \mathrm{m}^{-3}, 126 \mathrm{ng} \mathrm{m}^{-3}\right)$, glyoxal (46-1200 $\left.\mathrm{ng} \mathrm{m}^{-3}, \quad 487 \mathrm{ng} \mathrm{m}^{-3}\right)$, methylglyoxal (88-2690 $\left.\mathrm{ng} \mathrm{m}^{-3}, 967 \mathrm{ng} \mathrm{m}^{-3}\right)$, n-nonanal $\left(0-500 \mathrm{ng} \mathrm{m}^{-3}\right.$, $\left.89 \mathrm{ng} \mathrm{m}^{-3}\right)$, and $\mathrm{n}$-decanal $\left(0-230 \mathrm{ng} \mathrm{m}^{-3}, 39 \mathrm{ng} \mathrm{m}^{-3}\right)$. These concentrations are among the highest ever reported in the urban and forest atmosphere. We found that gaseous $\alpha$-dicarbonyls (glyoxal and methylglyoxal) are more than 20 times more abundant than particulate carbonyls and that glycolaldehyde is one order of magnitude more abundant than in aerosol phase. In contrast, hydroxyacetone and normal aldehydes (nonanal and decanal) are equally present in both phases. Time-resolved variations of carbonyls did not show any a clear diurnal pattern, except for hydroxyacetone.
\end{abstract}

We found that glyoxal, methylglyoxal and glycolaldehyde positively correlated with levoglucosan (a tracer of biomass burning), suggesting that a contribution from field burning of agricultural wastes (wheat crops) is significant for the bifunctional carbonyls in the atmosphere of Mt. Tai. Upward transport of the pollutants to the mountaintop from the low lands in the North China Plain is a major process to control the distributions of carbonyls in the upper atmosphere over Mt. Tai.

\section{Introduction}

Bi-functional carbonyls such as glyoxal and methylglyoxal are semi-volatile and abundantly present as gaseous phase in the urban and forest atmosphere (Matsunaga et al., 2004; Ieda et al., 2006; Ortiz et al., 2006; Volkamer et al., 2007; Dai et al., 2012; Okuzawa et al., 2007). They are produced by the oxidation of volatile organic compounds (VOC) released from anthropogenic activities, biogenic processes and burning sources either via combustion and photochemical processes (Carlier et al., 1986; Christensen et al., 2000; Grosjean et al., 2002). In particular, hydroxyacetone and $\alpha$ dicarbonyls (glyoxal and methylglyoxal) are produced by the oxidation of aromatic hydrocarbons and hydroxy carbonyls (Smith et al., 1998, 1999; Kleindienst et al., 2004). 
Isoprene also produces carbonyls by the oxidation with $\mathrm{OH}$ radicals (Carlier et al., 1986; Spaulding et al., 2003; Carlton et al., 2006, 2009). Some carbonyls such as $\alpha$-dicarbonyls that are produced by gas phase oxidation of VOC can also be present as aerosols (Kawamura and Yasui, 2005; Kawamura et al., 2010) due to their high effective Henry's law constant (e.g., $>3.6 \times 10^{5} \mathrm{M} \mathrm{atm}^{-1}$ for glyoxal) (Betterton and Hoffmann, 1988; Carlton et al., 2007) and the formation of hydrate (gem-diol) (Matsunaga and Kawamura, 2000) and/or oligomer formation of dicarbonyls in aerosols (Loeffler et al., 2006). Aqueous-phase reactive uptake of dicarbonyls has been proposed as a source of organic aerosol $(\mathrm{Fu}$ et al., 2008b, 2009).

Some dicarbonyls can serve as precursors of oxalic acid that is the most abundant organic species present in atmospheric particles (Kawamura and Ikushima, 1993; Kawamura and Usukura, 1993; Kawamura and Yasui, 2005). $\alpha$ Dicarbonyls such as glyoxal can form oligomers (Liggio et al., 2005; Loeffler et al., 2006). Oxalic acid and other small dicarboxylic acids are produced in cloud and/or aerosol by aqueous phase reactions (Warneck, 2003; Carlton et al., 2007; Legrand et al., 2007). The reaction products of carbonyls are water-soluble and thus act as cloud condensation nuclei $(\mathrm{CCN})$. They may play a role in the radiative forcing of aerosols and affect on climate change (Ramanathan et al., 2001).

Bifunctional carbonyls such as glycolaldehyde, hydroxyacetone, glyoxal and methylglyoxal have been studied in the urban atmosphere as abundant gaseous components (Ortiz et al., 2006; Okuzawa et al., 2007). However, the distributions of those carbonyls are rarely studied in the high mountain atmosphere influenced from urban activities and agricultural burning, in particular, in the free troposphere. In this study, we conducted the observation study on $\alpha$ dicarbonyls, hydroxy carbonyls, nonanal and decanal at the summit of Mt. Tai in the North China Plain during early summer when field burning of agricultural wastes was extensive. Both gaseous and particulate carbonyls were collected every three hours and determined using a capillary gas chromatography after two-step derivatization. Here, we report the timeresolved variations of glycolaldehyde, hydroxyacetone, glyoxal, methylglyoxal, nonanal and decanal (chemical structures are shown in Fig. 1) and discuss their sources and formation processes in the free troposphere.

The data of glyoxal will be compared with those obtained by the in situ measurements by MAX-DOAS at the top of Mt. Tai. The data of bifunctional carbonyls will be also compared with oxalic and glyoxylic acids determined in the aerosol samples that were simultaneously collected at the summit of Mt. Tai to discuss the photochemical linkage between gaseous bifunctional carbonyls and oxalic acid, the latter is the most abundant organic aerosol species.

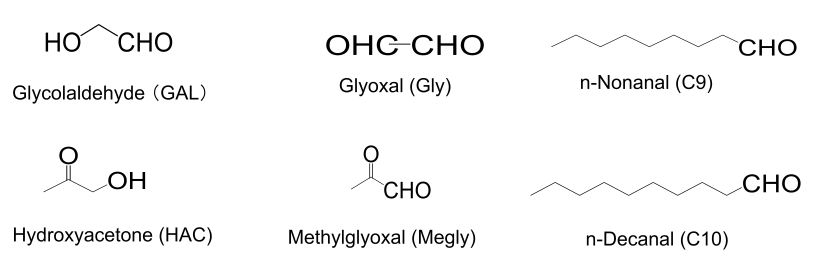

Fig. 1. Chemical structures of carbonyl compounds determined in this study.

\section{Experimental}

Mt. Tai (elevation: $1534 \mathrm{~m}$ above sea level, $36.25^{\circ} \mathrm{N}$ and $117.10^{\circ} \mathrm{E}$ ) is located in Shandong Province, Central East China (CEC). It is an independent peak in the CEC region (see Fig. 2 for map) and the mountaintop often stays within the free troposphere at night (Takigawa et al., unpublished results). As part of the Mount Tai Experiment 2006 campaign (MTX2006) in early summer (Kanaya et al., 2013), threehour samplings were performed for gaseous and particulate semi-volatile carbonyls from 2-5, 23-24 and 25 June 2006 at the balcony of two-story building of the observatory $(\sim 10$ $\mathrm{m}$, above ground level) on the top of Mt. Tai.

Figure 3 presents outlines of the sampling system using two-step filters and URG filter pack with a flow rate of $16.7 \mathrm{~L} \mathrm{~min}^{-1}$. Particulate carbonyls were collected on a quartz filter (1st filter) whereas gaseous carbonyls were collected on a quartz filter (2nd filter) impregnated with Obenzylhydroxylamine (BHA). Two sets of blanks for gas and particles were taken during the campaign. After the sample collection, filter samples (36 samples for gas and particles, respectively) were stored in a clean glass vial $(50 \mathrm{~mL})$ with a Teflon-lined screw cap at $-20^{\circ} \mathrm{C}$ in a freezer room. Before the sample collection, quartz filters $(45 \mathrm{~cm}$ in diameter) were combusted to remove organic contaminants and stored in the clean vials. For the collection of gaseous carbonyls, quartz filter was impregnated with BHA reagent in acetonitrile (Matsunaga et al., 2004) and stored in a clean glass vial until the sampling.

In the laboratory, the quartz filter that collect particulate bifunctional carbonyls was extracted with methylene chloride/acetonitrile $(1: 1)$ mixture and the extracts were concentrated with a rotary evaporator under vacuum, to which $2 \mathrm{~mL}$ of BHA solution (4\% in acetonitrile) were added to derive benzyl hydroxy oximes (BH oximes) of carbonyls and stood for $24 \mathrm{~h}$ at room temperature. The $\mathrm{BH}$ oximes were dried using a rotary evaporator under vacuum and then dissolved in ethyl acetate. The BHA-impregnated filter that collect gaseous carbonyls was handled as follows. BHA solution in acetonitrile was added to the filter, which stood for $24 \mathrm{~h}$ at room temperature to complete the formation of the BH oxime derivatives. The derivatives were extracted with acetonitrile, concentrated under vacuum and then dissolved in ethyl acetate. The extracts were further concentrated 
Table 1. Recoveries (\%) of authentic carbonyls from BHA impregnated filter.

\begin{tabular}{ll}
\hline Compounds & Recovery $(\%, \mathrm{AVG} \pm \mathrm{SD})$ \\
\hline Glycolaldehyde & $65.9 \pm 22.3$ \\
Hydroxyacetone & $82.0 \pm 17.3$ \\
n-Nonanal & $89.1 \pm 1.9$ \\
n-Decanal & $93.1 \pm 11.9$ \\
Glyoxal & $86.2 \pm 9.2$ \\
Methylglyoxal & $85.4 \pm 8.2$ \\
\hline
\end{tabular}

under nitrogen flow and the hydroxyl group of $\mathrm{BH}$ oxime was reacted with $\mathrm{N}, \mathrm{O}-\mathrm{Bis}$ (trimethylsilyl)trifluoroacetamide (BSTFA, $50 \mu \mathrm{L}$ ) at $60^{\circ} \mathrm{C}$ for $1 \mathrm{~h}$ to derive the TMS ether. In the case of hydroxy aldehyde (e.g., glycolaldehyde), reactions were preceded as follows:

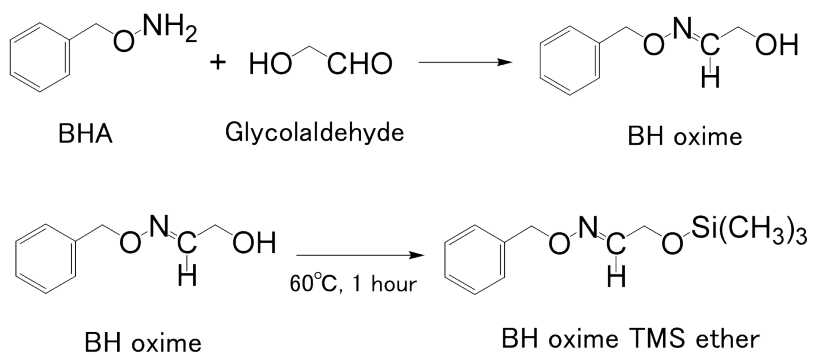

After the two-step derivatization with BHA and BSTFA, the carbonyl $\mathrm{BH}$ oxime derivatives were determined using a gas chromatography (Matsunaga and Kawamura, 2000; Okuzawa et al., 2007).

In order to check the recoveries of gaseous and particulate carbonyls in triplicate, 6 authentic carbonyls (glycolaldehyde, hydroxyacetone, glyoxal, methylglyoxal, n-nonanal, ndecanal, glyoxal and methylglyoxal) were added onto the BHA impregnated quartz filter and neutral quartz filter following the analytical procedures described above. Table 1 shows the recoveries of carbonyls that were spiked to the BHA impregnated filter. The results indicate that the recoveries of gaseous carbonyls are more than $80 \%$, except for glycoladehydes $(66 \%)$. In contrast, the recoveries of carbonyls spiked to neutral filter that collect particles were more than $86 \%$ except for glycolaldehyde (54\%) and glyoxal (50\%) (see Table 2). Some semivolatile aldehydes such as glycolaldehydes and glyoxal may be in part evaporated from the aerosol particles and trapped on the BHA impregnated filter during the sampling. Thus, gaseous carbonyls may potentially be overestimated whereas particulate carbonyls may be underestimated. However, glyoxal and some other bifunctional carbonyls can form hydrated forms (e.g., gem-diol) and oligomers, which partition into particles. Thus, the recoveries of particulate carbonyls may be better than those obtained for authentic carbonyls from the neutral filter (Table 2). The concentrations of carbonyls reported here are corrected for the blanks.
Table 2. Recoveries (\%) of authentic carbonyls from quartz filter.

\begin{tabular}{ll}
\hline Compounds & Recovery $(\%, \mathrm{AVG} \pm \mathrm{SD})$ \\
\hline Glycolaldehyde & $54.1 \pm 16.6$ \\
Hydroxyacetone & $86.9 \pm 4.9$ \\
n-Nonanal & $90.3 \pm 9.4$ \\
n-Decanal & $94.9 \pm 7.8$ \\
Glyoxal & $50.1 \pm 4.0$ \\
Methylglyoxal & $90.8 \pm 9.8$ \\
\hline
\end{tabular}

During the MTX2006 campaign, the Multi-Axis Differential Optical Absorption Spectroscopy (MAX-DOAS) system was also operated at the top of Mt. Tai (Inomata et al., 2008; Irie et al., 2008). The MAX-DOAS system has a telescope unit with five telescopes, which were all directed south, but the elevation angles were fixed at $-5^{\circ}, 5^{\circ}, 10^{\circ}, 20^{\circ}$, and $30^{\circ}$, respectively. The telescope with an elevation angle of $-5^{\circ}$ looked down from the top of Mt. Tai toward the ground of Tai' an city $\left(116.03^{\circ} \mathrm{E}, 117.98^{\circ} \mathrm{E}\right.$, altitude $\left.126 \mathrm{~m}\right)$ located ca. $10 \mathrm{~km}$ south of Mt. Tai in the North China Plain. To acquire the reference spectrum with the instrument line shape same as that of off-axis measurements, a mirror was automatically inserted into each sight of the telescopes, altering the viewing direction to the zenith sky. A six min zenith-sky measurement was made every $30 \mathrm{~min}$. The five different spectra measured were projected onto the 2-D CCD detector, simultaneously. In a $30 \mathrm{~min}$ cycle, two different wavelength regions of $310-377 \mathrm{~nm}$ (for the first $15 \mathrm{~min}$ ) and $425-490 \mathrm{~nm}$ (for the last $15 \mathrm{~min}$ ) were measured alternatively. The spectral resolution (FWHM) was estimated to be about $0.2-0.3 \mathrm{~nm}$. The spectral fitting window of $436-457 \mathrm{~nm}$ was analyzed by the DOAS method and then the vertical profile retrieval was done to retrieve vertical profiles of glyoxal mixing ratio in the lower troposphere (Inomata et al., 2008; Irie et al., 2008). The mean glyoxal volume mixing ratios in the layer of $1-$ $2 \mathrm{~km}$ above the ground (126 $\mathrm{m}$ a.s.l.) are used in this study. Although the altitude is different from that for the direct sampling measurements at the summit of Mt. Tai, MAX-DOAS glyoxal data can be used to compare with the temporal variations that are obtained from the filter sampling and GC measurement.

The meteorological parameters (temperature, relative humidity, wind direction/speeds and precipitation) as well as air mass trajectories and fire spots are presented in Kawamura et al. (2013). Briefly, the ambient temperature increased up to $24^{\circ} \mathrm{C}$ in daytime and decreased down to $8{ }^{\circ} \mathrm{C}$ at night. The relative humidity increased from ca. $50 \%$ in daytime to $>95 \%$ at night. During early June, extensive fire spots were observed from a space (Kawamura et al., 2013) in the North China Plain, in which field burning of agricultural waste (harvested wheat straws) was densely observed (Kanaya et al., 2013). 


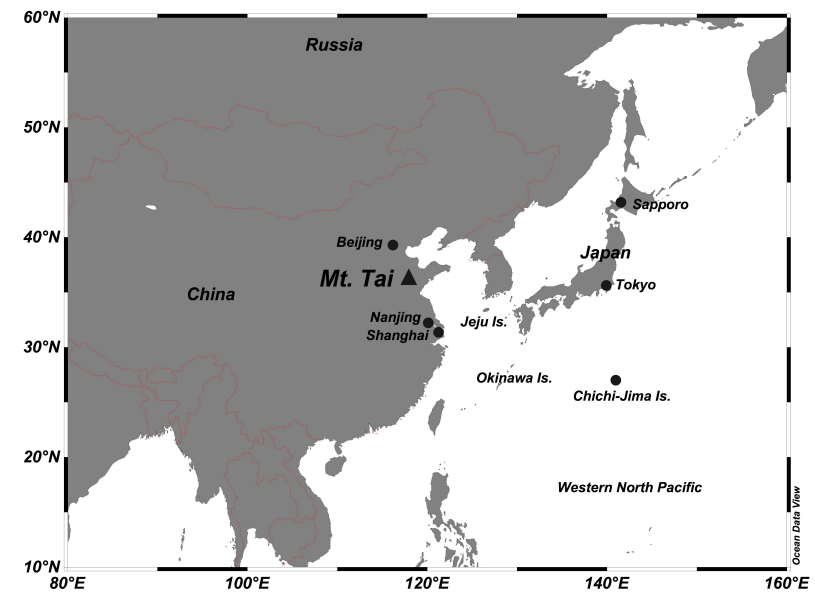

Fig. 2. A map of East Asia with the sampling location of Mt. Tai in the North China Plain.

\section{Result and discussion}

\subsection{Concentrations and distributions of 6 carbonyls}

We detected 6 carbonyls (glycolaldehyde, hydroxyacetone, glyoxal, methylglyoxal, n-nonanal and n-decanal) in the gas and particle phases in the atmosphere of Mt. Tai. Table 3 shows average concentrations of these carbonyls with concentration ranges. Among the gaseous carbonyls detected, methylglyoxal was found as the most abundant carbonyl followed by glyoxal and glycolaldehyde. Hydroxyacetone is roughly one third of glycolaldehyde. Straight-chain aldehydes such as nonanal and decanal are several times less abundant than methylglyoxal and glyoxal. In contrast, hydroxyacetone was the most abundant carbonyls detected in the particle phase, followed by n-nonanal and n-decanal. Methylglyoxal and glyoxal are among the least abundant carbonyls in the particles. We found that gaseous carbonyls are several to 20 times more abundant than particle phase carbonyls in the atmosphere of Mt. Tai, except for hydroxyacetone, n-nonanal and n-decanal which are equally present in both phases or more abundant in aerosol phase (n-decanal) (see Table 3). Higher concentrations of $\alpha$-dicarbonyls (glyoxal and methylglyoxal) in gas phase than in particles have been reported from urban Tokyo (Okuzawa et al., 2007) and from the forest atmosphere (Matsunaga et al., 2004; Ieda et al., 2006) using a denuder technique for the collection of gaseous carbonyls.

Interestingly, an opposite trend was obtained in semiurban Saitama, located ca. $30 \mathrm{~km}$ northwest of the metropolitan Tokyo area, with higher concentrations of carbonyls in particles (several times higher in particles than gas phase) (Ortiz et al., 2006), in which particulate carbonyls are slightly higher than our results but gaseous carbonyls are significantly lower than ours (e.g., concentration of gaseous methylglyoxal in Saitama is ca. 50 time lower than that of Mt. Tai). In the study of Saitama, PFBHA-coated denuder

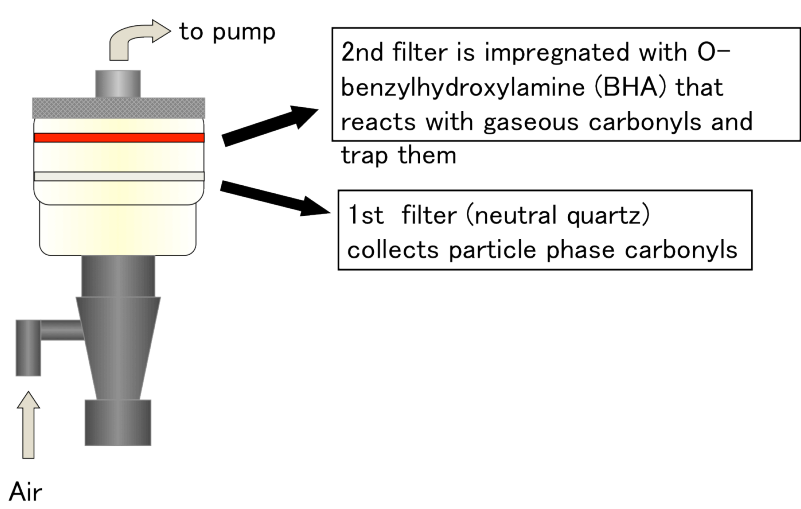

Fig. 3. Outlines of sampling system for collecting particulate and gaseous carbonyls.

Table 3. Concentrations $\left(\mathrm{ng} \mathrm{m}^{-3}\right)$ of gaseous and particulate carbonyls in the air of Mt. Tai.

\begin{tabular}{lrrrr}
\hline Carbonyls & Minimum & Maximum & Average & Median \\
\hline Gas phase & & & & \\
\hline Glycolaldehyde & 0.0 & 826 & 303 & 300 \\
Hydroxyacetone & 0.0 & 579 & 126 & 55 \\
n-Nonanal & 0.0 & 500 & 89 & 64 \\
n-Decanal & 0.0 & 230 & 39 & 27 \\
Glyoxal & 46 & 1200 & 487 & 375 \\
Methylglyoxal & 88 & 2690 & 967 & 968 \\
\hline Particle phase & & & & \\
\hline Glycolaldehyde & 0.0 & 208 & 37 & 32 \\
Hydroxyacetone & 0.0 & 471 & 97 & 81 \\
n-Nonanal & 0.0 & 281 & 63 & 39 \\
n-Decanal & 0.0 & 513 & 60 & 25 \\
Glyoxal & 0.0 & 137 & 31 & 26 \\
Methylglyoxal & 0.0 & 75 & 21 & 14 \\
\hline
\end{tabular}

was used for the collection of gaseous carbonyls, whereas PFBHA-impregnated filter was used for the collection of particulate carbonyls using a potassium iodide annular denuder (Ortiz et al., 2006).

Table 4 compares the average concentrations of carbonyls with those reported from other sampling sites. Concentrations of gaseous hydroxy carbonyls (glycolaldehyde and hydroxyacetone) in the Mt. Tai atmosphere are lower (ca. one third) than those reported in urban Tokyo (Okuzawa et al., 2007) but 3-4 times higher than those from the atmosphere in the forest of Moshiri, Hokkaido, Japan (Matsunaga et al., 2004). In contrast, concentrations of $\alpha$-dicarbonyls in Mt. Tai are slightly higher than those from the Tokyo atmosphere (Okuzawa et al., 2007) and 10 times higher than those from the forest atmosphere in Moshiri, Hokkaido (Matsunaga et al., 2004). Concentrations of gaseous nonanal and decanal in the Mt. Tai atmosphere are slightly lower than those of the forest atmosphere of Moshiri where a mixed forest of 

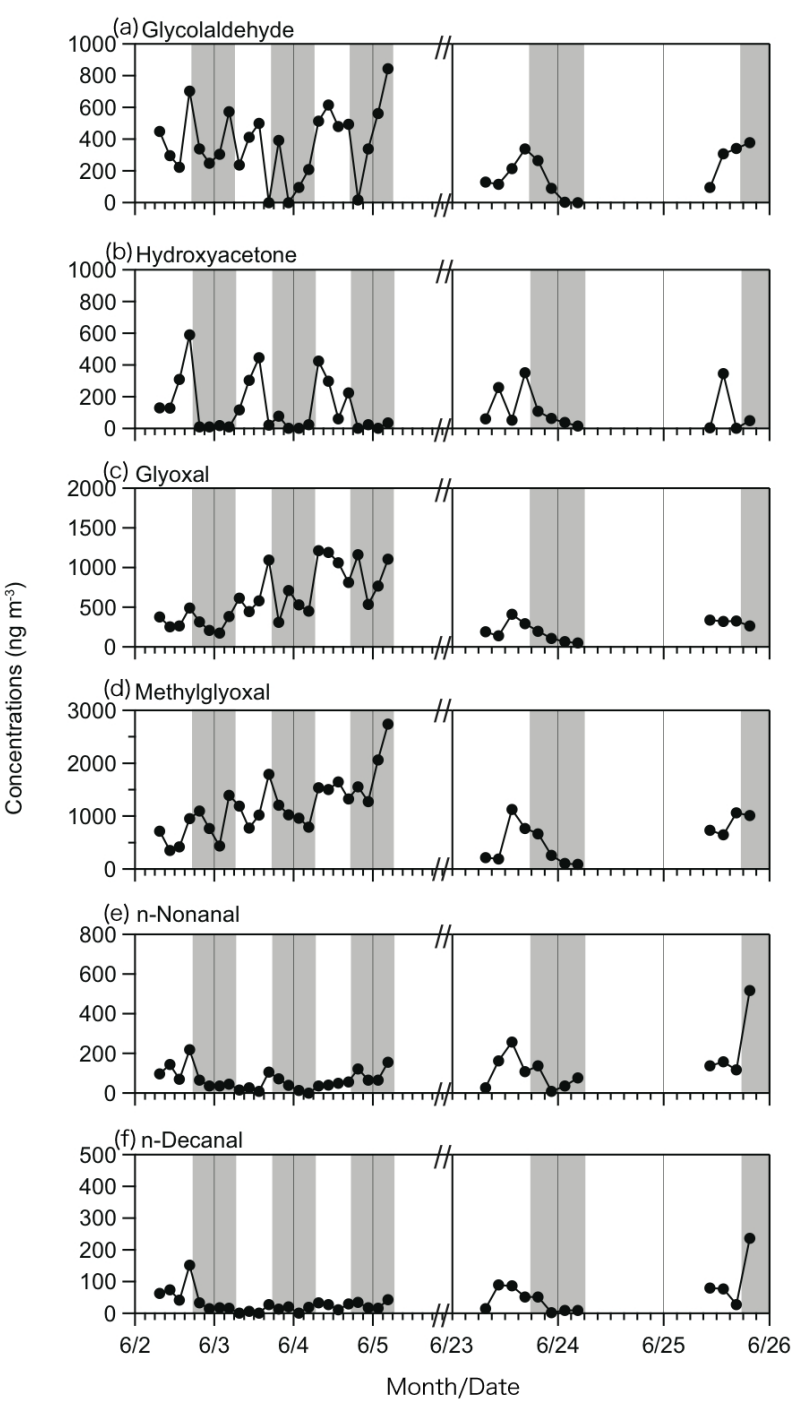

Fig. 4. Time-resolved variations of concentrations of gaseous carbonyl compounds; (a) glycolaldehyde, (b) hydroxyacetone, (c) glyoxal, (d) methylglyoxal, (e) n-nonanal and (f) n-decanal.

Quercus crispula and Picea glehnii mast exists (Matsunaga et al., 2004). On the other hand, concentrations of particulate carbonyls in the Mt. Tai aerosols are several times higher than the forest aerosols from Tomakomai, Hokkaido (Ieda et al., 2006), except for hydroxyacetone (almost same) and glycolaldehyde (50\% higher than Tomakomai).

It is of interest to note that concentrations of gaseous $\alpha$-dicarbonyls in Mt. Tai are slightly higher than those ( $160 \mathrm{ng} \mathrm{m}^{-3}$ for glyoxal and $670 \mathrm{ng} \mathrm{m}^{-3}$ for methylglyoxal) reported in heavily polluted Xi'an, China during summer (Dai et al., 2012), but much lower than those (1880 $\mathrm{ng} \mathrm{m}^{-3}$ and $4960 \mathrm{ng} \mathrm{m}^{-3}$, respectively) reported in semi-rural area from Rome, Italy (Possanzini et al., 2007). In the latter case, a potassium iodide-coated annular denuder was placed upstream of the DNPH-coated silica gel Sep-Pak cartridge (Possanzini et al., 2007).

\subsection{Time-resolved variations of carbonyl compounds}

Figure 4 presents time-resolved variations of 6 carbonyls in gas phase. In general, the concentrations of carbonyls did not show clear daytime maxima although hydroxyacetone seems to maximize in daytime. These results are not consistent with the observation from urban Tokyo, in which daytime maxima of glycolaldehyde, hydroxyacetone, glyoxal and methylglyoxal have clearly been obtained together with the daytime maxima of oxidants (Okuzawa et al., 2007). These comparisons may suggest that the sources and formation pathways of bifunctional carbonyls in the atmosphere of Mt. Tai are not the same with those of the urban atmosphere. In the summit of Mt. Tai, long-range transport may be more important than in situ photochemical production via the oxidation of various VOCs in the atmosphere. In the North Chain Plain, field burning of agricultural waste (wheat straw) is common in early summer after the harvesting of wheat (Kanaya et al., 2013) and biomass-burning products such as levoglucosan have been abundantly detected in the mountaintop aerosols during MTX 2006 campaign (Fu et al., 2008a, 2012).

Interestingly, we found a good positive correlation between levoglucosan (an excellent tracer of biomass burning) (Simoneit, 1999) with glyoxal (correlation coefficient, $r=$ $0.82)$, methylglyoxal $(r=0.78)$, and glycolaldehyde $(r=$ 0.63 ); levoglucosan data are from Fu et al. (2012). Figure 5 presents relationships between glyoxal and levoglucosan, and methylglyoxal and levoglucosan. However, weaker correlations $(r=0.55$ for glyoxal, $r=0.42$ for methylglyoxal) were obtained between levoglucosan and particulate $\alpha$-dicarbonyls (Kawamura et al., 2013). These results suggest that bifunctional carbonyls except for hydroxyacetone are mainly derived from biomass burning in the North China Plain where field burning of wheat straws are extensively operated in the early summer and the biomass burning plumes are transported to the mountaintop by upwind in daytime. However, there is no correlation between hydroxyacetone and levoglucosan $(r=0.15)$. On the other hand, nonanal and decanal showed a weak negative relationship with levoglucosan $(r=0.19-0.20)$. These aldehydes may be derived from the plant emissions (Matsunaga et al., 2004) rather than biomass burning emissions.

Figure 6 presents comparison of gaseous and particulate carbonyls in the time-resolved variations in the Mt. Tai atmosphere for the period of 2-5 June 2006. The variations of particulate carbonyls did not show a diurnal trend, except for n-aldehydes (nonanal and decanal, see Fig. 6d) and $\alpha$-dicarbonyls (glyoxal and methylglyoxal, see Fig. 6f) that showed daytime maxima on 4 June. As already stated above, most carbonyls are present as gases in the atmosphere of Mt. Tai, although particulate concentrations of n-nonanal 
Table 4. Comparison of averaged carbonyl concentrations $\left(\mathrm{ng} \mathrm{m}^{-3}\right)$ of this study with those reported in the urban, suburban and forest atmospheres.

\begin{tabular}{lrrrrr}
\hline Compounds & $\begin{array}{r}\text { This study } \\
\text { (2-5 June) }\end{array}$ & $\begin{array}{r}\text { Urban, Jul } \\
\text { and Aug 2004 } \\
\text { Tokyo, Japan }\end{array}$ & $\begin{array}{r}\text { Suburban, Jul } \\
\text { and Aug 2004 } \\
\text { Saitama, Japan }\end{array}$ & $\begin{array}{r}\text { Moshiri Exp. } \\
\text { Forest Aug 2002 } \\
\text { Hokkaido, Japan }\end{array}$ & $\begin{array}{r}\text { Tomakomai Forest } \\
\text { Tower (22 m) Sep 2003 } \\
\text { Hokkaido, Japan }\end{array}$ \\
\hline Glycolaldehyde & 303 & 1550 & 19 & 72 & 203 \\
Hydroxyacetone & 126 & 362 & 16 & 48 & 126 \\
n-Nonanal & 89 & 584 & - & 102 & - \\
n-Decanal & 39 & 123 & 13 & 44 & 60 \\
Glyoxal & 487 & 406 & 19 & 83 & 155 \\
Methylglyoxal & 967 & 797 & - & - \\
\hline
\end{tabular}

${ }^{1}$ Okuzawa et al. (2007), ${ }^{2}$ Ortiz et al. (2006), ${ }^{3}$ Matsunaga et al. (2004), ${ }^{4}$ Ieda et al. (2006).
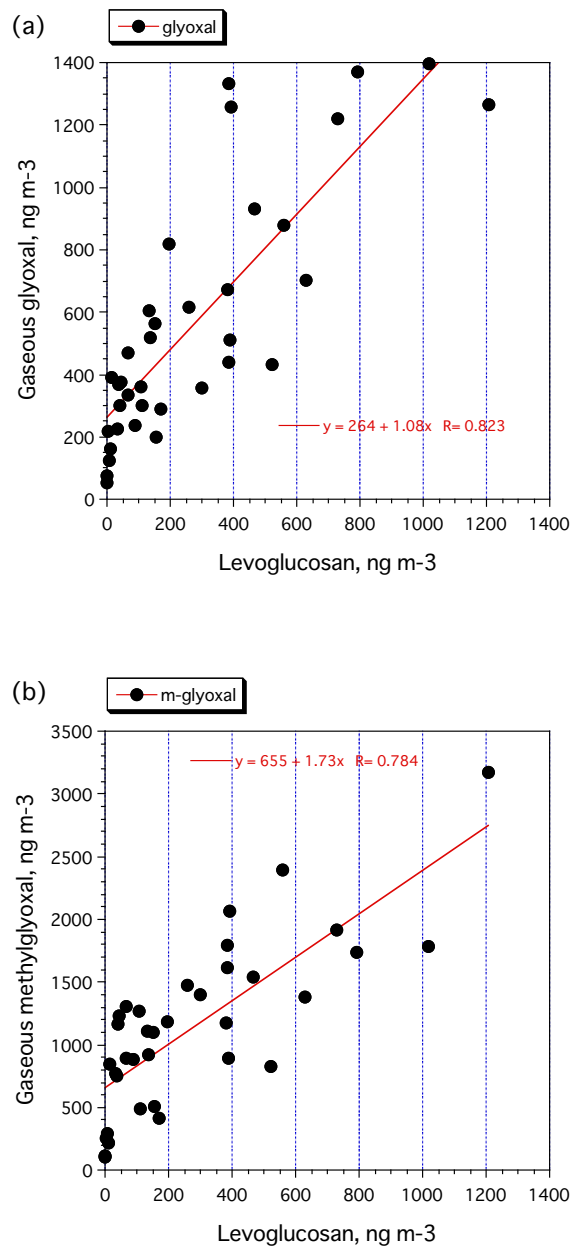

Fig. 5. Relationships between levoglucosan in the Mt. Tai aerosols (Fu et al., 2012) and (a) gaseous glyoxal and (b) gaseous methylglyoxal in the atmosphere of Mt. Tai. The data of levoglucosan were obtained by GC/MS measurement of the aerosol filter samples collected simultaneously using a high volume air sampler at Mt. Tai (Fu et al., 2012). and n-decanal are sometimes equivalent to those of gaseous forms.

\subsection{MAX-DOAS measurement of glyoxal and its comparison to filter sampling/GC measurements of gaseous glyoxal}

In Fig. 7, the glyoxal mixing ratios (pptv) derived from MAX-DOAS observations are plotted as a function of the sampling time to compare with those obtained from the filter sampling/GC determination. The MAX-DOAS data represent a mean concentration of glyoxal for the layer of $1-2 \mathrm{~km}$ above the ground surface, whereas the filter sampling/GC determination data give the glyoxal concentrations at the mountain top site. The $3 \mathrm{~h}$ average concentrations are higher at the mountaintop than in the $1-2 \mathrm{~km}$ layer between the mountaintop and ground surface in Tai' an as seen in Fig. 7b, except for one point in the evening of 2 June. Although the altitude and area of MAX-DOAS observation are different from those of filter sampling site (1534 $\mathrm{m}$ a.s.1.) and thus could lead to a systematic difference in the glyoxal mixing ratios between the two methods, we found a positive correlation between the two mixing ratios with correlation coefficient of 0.58 (Fig. 8). This result suggests that the temporal variation of glyoxal in the troposphere of $1-2 \mathrm{~km}$ is similar to that in the atmosphere of Mt. Tai.

However, the mixing ratios of MAX-DOAS glyoxal are ca. 5 times lower than those of glyoxal determined by the filter sampling/GC method (Fig. 8). This difference may suggest that glyoxal levels in the atmosphere of Mt. Tai are much higher than those in the near-ground atmosphere possibly due to more production of glyoxal in the upper atmosphere over the North China Plain. Although MAX-DOAS measurements did not directly support the photochemical production of glyoxal, it is of interest to note that MAX-DOAS data showed that glyoxal concentrations increased in the afternoon (Fig. 7b), suggesting that glyoxal is photochemically produced in the atmosphere. Alternatively, the significant difference between two methods may suggest that the distributions of glyoxal are not homogeneous between the 

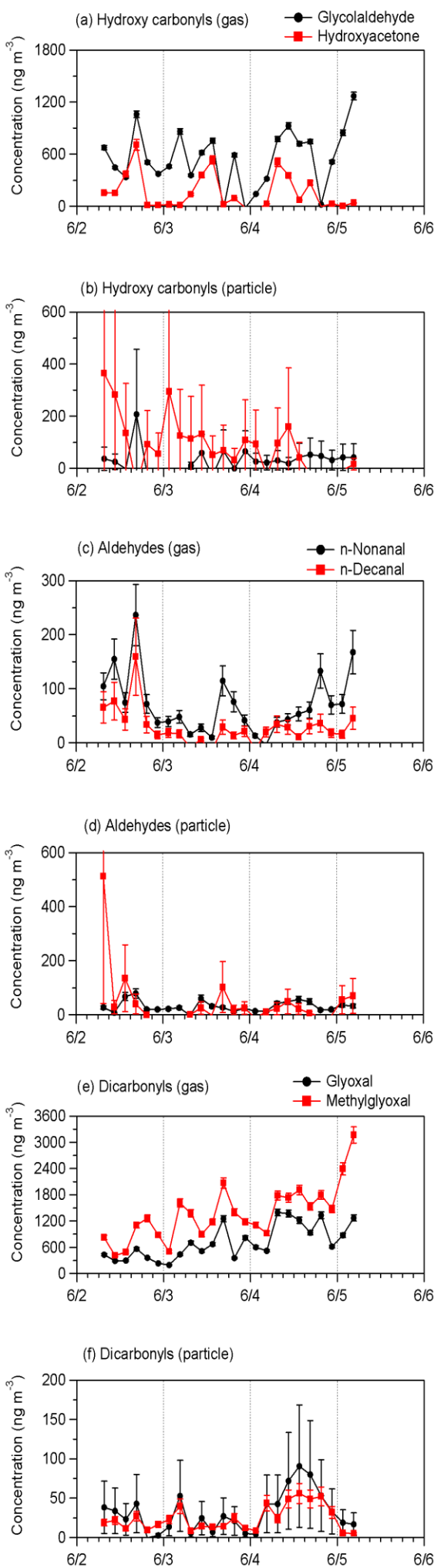

Fig. 6. Comparison of time-resolved variations for gaseous and particulate carbonyls in the Mt. Tai atmosphere as three types of carbonyls (hydroxy carbonyls, n-aldehydes and $\alpha$-dicarbonyls).
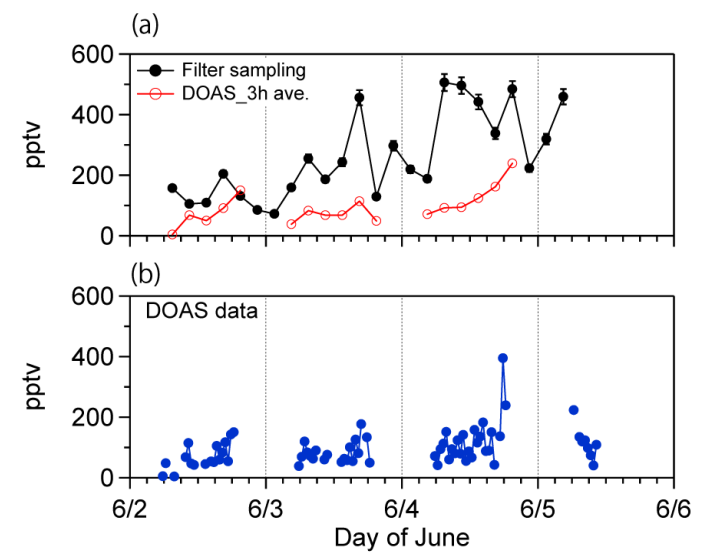

Fig. 7. (a) Mixing ratios of glyoxal (pptv) determined by filter sampling/GC method and MAX-DOAS. The MAX-DOAS data are averaged for $3 \mathrm{~h}$ intervals. (b) Mixing ratios of glyoxal obtained from MAX-DOAS every $30 \mathrm{~min}$.

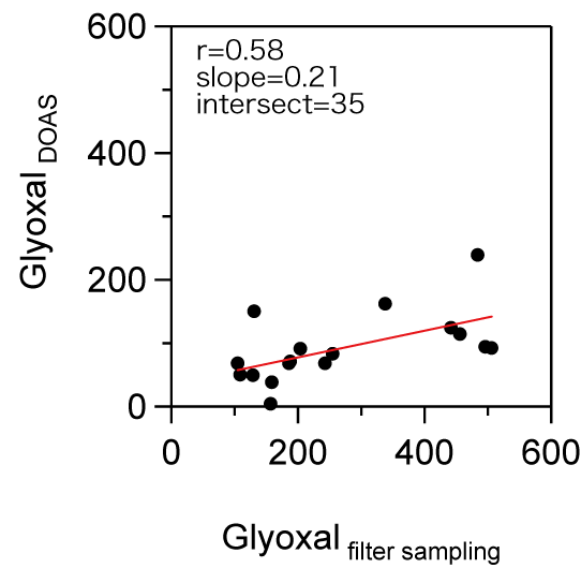

Fig. 8. Relationship between the concentrations (pptv) of glyoxal by MAX-DOAS and filter sampling/GC methods.

mountaintop site and ground level. It is also important to note that due to a very thick aerosol layer in this polluted region MAX-DOAS data may have significant uncertainties, potentially causing lower concentrations. Further studies are needed to better understand the concentrations and vertical profiles of glyoxal over the North China Plain.

\subsection{Comparison of gaseous $\alpha$-dicarbonyls (this study) with particulate $\alpha$-dicarbonyls determined in the TSP samples}

Because the accuracy of particulate carbonyls determined in this study is not high enough to discuss gas/particle partitioning (see Fig. 6), we use here the data sets of $\alpha$ dicarbonyls obtained from the analyses of the TSP samples collected every $3 \mathrm{~h}$ simultaneously at the same sampling site of Mt. Tai and analyzed using dibutoxy derivatives and GC 

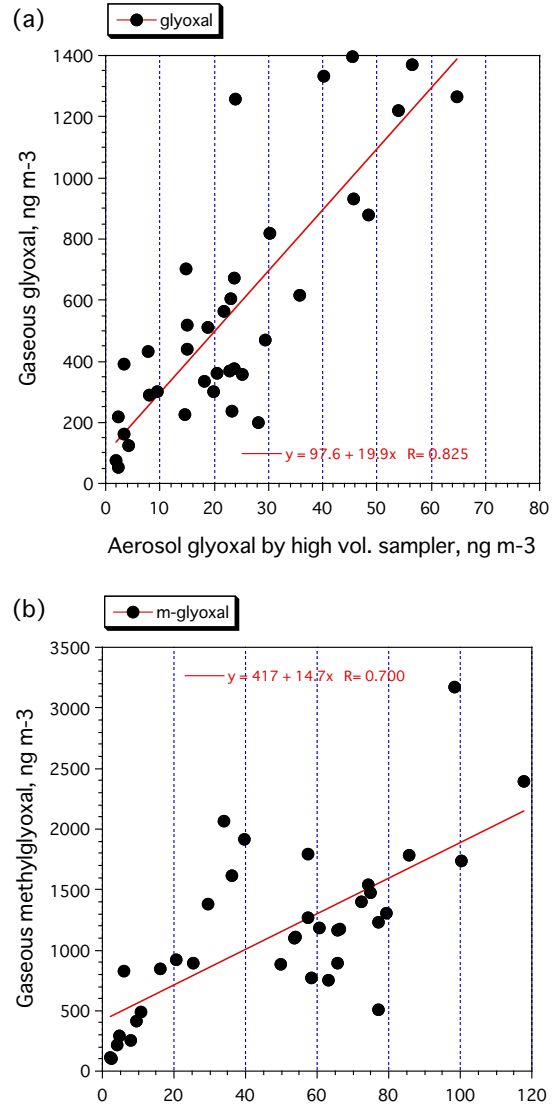

Aerosol methylglyoxal by high vol. sampler, $\mathrm{ng} \mathrm{m}-3$

Fig. 9. Relationship between the concentrations of (a) gaseous glyoxal $\left(\mathrm{ng} \mathrm{m}^{-3}\right)$ measured in this study and particulate glyoxal measured in aerosol samples (TSP) from Mt. Tai and (b) gaseous methylglyoxal and particulate methylglyoxal. The data of particulate glyoxal and methylglyoxal were obtained from the aerosol samples, which were collected simultaneously at Mt. Tai and analyzed by capillary GC using derivatization to dibutoxy acetals (Kawamura et al., 2013).

determination (Kawamura et al., 2013). Figure 9a shows relationship between gaseous glyoxal determined in this study and particulate glyoxal determined in the aerosol filter samples collected using a high volume air sampler at the summit of Mt. Tai. A good positive correlation was found between the two data sets (correlation coefficient: $r=0.83$ ). We also found that gaseous glyoxal concentrations are ca. 20 times higher than those of particulate glyoxal, again indicating that major portion of this $\alpha$-dicarbonyl is present as gas phase in the mountain atmosphere. This conclusion is consistent with the previous studies from forest and urban areas (Matsunaga et al., 2004; Ieda et al., 2006; Okuzawa et al., 2007). Although similar positive correlation was obtained for methylglyoxal (Fig. 9b), the correlation coefficient $(r=0.70)$ is smaller than that of glyoxal $(r=0.83)$.

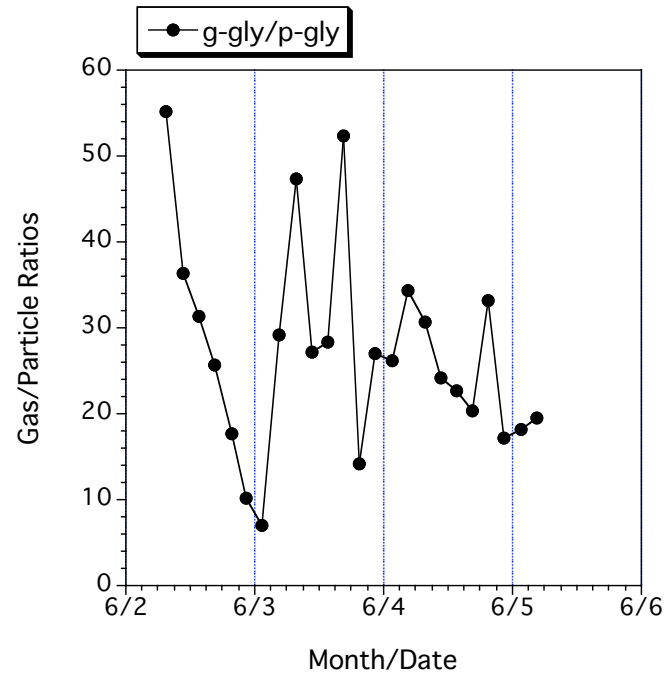

Fig. 10. Time-resolved variation of gas/particle partitioning of glyoxal in the atmosphere of Mt. Tai. Particulate glyoxal data are from Kawamura et al. (2013).

Although gas-phase carbonyls are always more abundant than particle-phase carbonyls throughout the campaign except for n-nonanal and n-decanal, we detected the diurnal changes in the gas/particle partitioning of glyoxal as shown in Fig. 10. The gas/particle ratios of glyoxal are higher in daytime and lower in nighttime, suggesting that gaseous glyoxal is in part transferred to the aerosol phase by adsorption and/or forming hydrates and/or oligomers during nighttime when the ambient temperature is lower and relative humidity is higher. However, we did not find a clear diurnal variation in the gas/particle ratios of methylglyoxal (data are not shown as a figure).

\subsection{Gaseous glyoxal and methylglyoxal as potential precursors of oxalic and glyoxylic acids in aerosols}

Oxalic acid is one of the most abundant organic species in aerosol particles. This organic acid can be emitted from fossil fuel combustion (Kawamura and Kaplan, 1987; Ho et al., 2007) and biomass burning (Legrand and de Angelis, 1996; Narukawa et al., 1999; Kundu et al., 2010), however, the most important source of oxalic acid is secondary production in the atmosphere via photochemical oxidation of various precursors (Ervens et al., 2004, 2008; Kawamura and Yasui, 2005; Carlton et al., 2007; Kawamura et al., 2010). Glyoxal and methylglyoxal are important precursors of oxalic acid and glyoxylic acid (Kawamura et al., 1996; Warneck, 2003; Ervens et al., 2011). Interestingly, we found a good correlation $(r=0.75)$ between gaseous glyoxal concentrations and particulate oxalic acid concentrations in the Mt. Tai atmosphere (see Fig. 11a). Much stronger correlation $(r=0.89)$ was obtained between gaseous methylglyoxal and particulate oxalic acid (Fig. 11b). These results may suggest 
that gaseous $\alpha$-dicarbonyls are taken in the aerosols during gas/particle portioning and are partly subjected to aqueous aerosol phase oxidation to result in oxalic acid.

In order to evaluate the above idea, the concentration ratios were taken for combinations of possible gaseous precursor and particle phase product. The product/precursor ratios for several combinations are plotted as a function of sampling time of $3 \mathrm{~h}$. As shown in Fig. 12a, oxalic acid/glyoxal ratios increased at night when ambient temperature decreased and relative humidity increased. The nighttime peaks of the product/precursor ratios on 2-5 June support the aqueous phase production of oxalic acid (HOOC-COOH) by the oxidation of glyoxal (HCO-CHO) that is transferred from gaseous phase to aerosol particles (Volkamer et al., 2007). Similar diurnal patterns were observed for another combination of product/precursor ratios. Fig. 12b shows an example for glyoxylic acid/glyoxal ratios. The nighttime peaks of the ratios suggest that glyoxal can be oxidized to result in glyoxylic acid (HCO-COOH) via the aqueous phase reaction (Warneck, 2003). Similar nighttime peaks were observed for $23-$ 24 June data (figures are not shown here). Further, we found the nighttime maxima of pyruvic acid/methylglyoxal ratios (the data are not shown as a figure), suggesting that pyruvic acid $\left(\mathrm{CH}_{3} \mathrm{COCOOH}\right)$ can be produced by the oxidation of methylglyoxal $\left(\mathrm{CH}_{3} \mathrm{COCHO}\right)$.

These results of our study support that the nighttime production of small organic acids from $\alpha$-dicarbonyls occurs in the atmosphere over Mt. Tai probably via aqueous phase reaction in aerosols. Production of oxalic acid in nighttime aerosols has been reported in urban New Delhi, India (Miyazaki et al., 2009) and suburban areas of China (He and Kawamura, 2010) based on day/night observation of dicarboxylic acids, which have been interpreted by aqueous phase oxidation of precursor organics including glyoxylic acid, although the correlation analyses with dicarbonyls were not performed.

It is important to note that large amounts of $\alpha$ dicarbonyls and oxalic acid are emitted from biomass burning (e.g.,Wittrock et al., 2006; Fu et al., 2008b; Myriokefalitakis et al., 2008). In fact, glyoxal and methylglyoxal showed good correlations with the biomass burning tracer (levoglucosan) as discussed above (see Fig. 5). Further, glyoxal and methylglyoxal concentrations significantly declined in late June (Fig. 4), when field burning of agricultural wastes near the Mt. Tai region was decreased and ended (Fu et al., 2012). Hence, field burning of wheat straws in the North China Plain seriously contribute to the high levels of glyoxal and methylglyoxal in the Mt. Tai region and its vicinity.

\section{Summary and conclusions}

Bifunctional carbonyls (glyoxal, methylglyoxal, glycolaldehyde and hydroxyacetone) and n-aldehydes (nonanal and octanal) were studied in the gas phase and particles in the at-
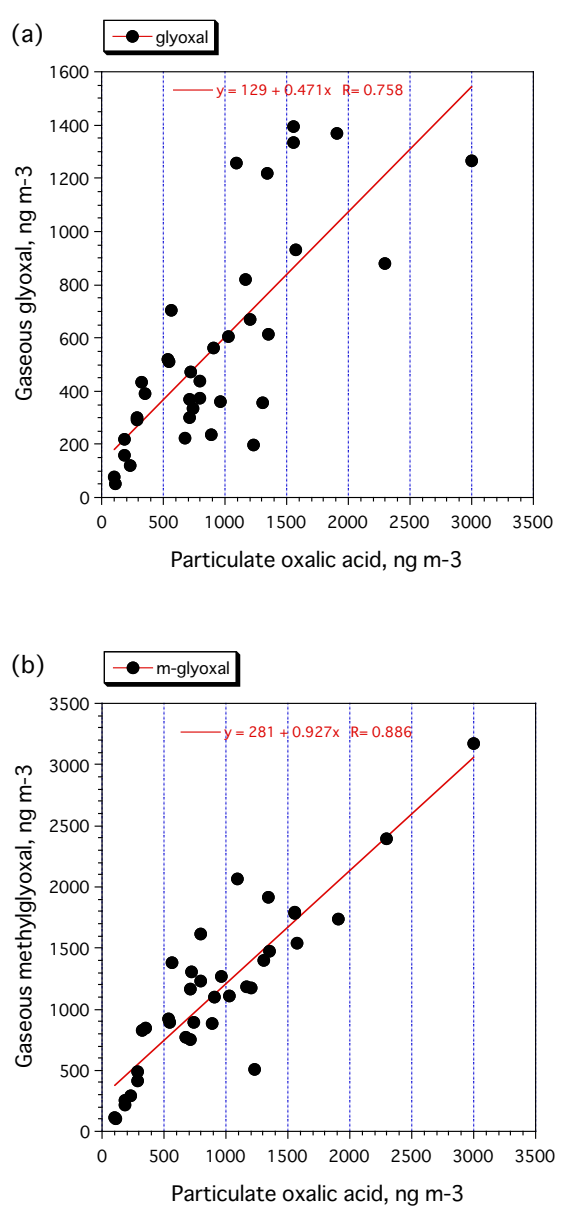

Fig. 11. Correlation plots for (a) gaseous phase glyoxal and particulate oxalic acid and (b) gaseous phase methylglyoxal and particulate oxalic acid in the atmosphere of Mt. Tai. The data of oxalic acid in aerosols are from Kawamura et al. (2013).

mosphere at the summit of Mt. Tai (elevation, $1534 \mathrm{~m}$ ) in the North China Plain during early summer. Gaseous phase carbonyls were found to be roughly ten times more abundant than particulate carbonyls. Methylglyoxal was found as the most abundant carbonyl followed by glyoxal and glycolaldehyde. Normal aldehydes were less abundant in gas phase, although they are more abundant than $\alpha$-dicarbonyls in aerosol phase. The gaseous and aerosol carbonyls were measured every $3 \mathrm{~h}$; however, we could not detect any clear daytime maximum in the diurnal variations, except for hydroxyacetone that showed a daytime peak. Instead, glyoxal, methylglyoxal and glycolaldehyde showed a positive correlation with levoglucosan, suggesting that the bifunctional carbonyls are mainly derived from biomass burning in the North China Plain where field burning of agricultural waste (wheat straw) were very active in early summer. The carbonyls are upward transported from the ground surface of the agricultural fields to the upper troposphere over Mt. Tai by the upwind. Gaseous carbonyls were found to correlate positively with 

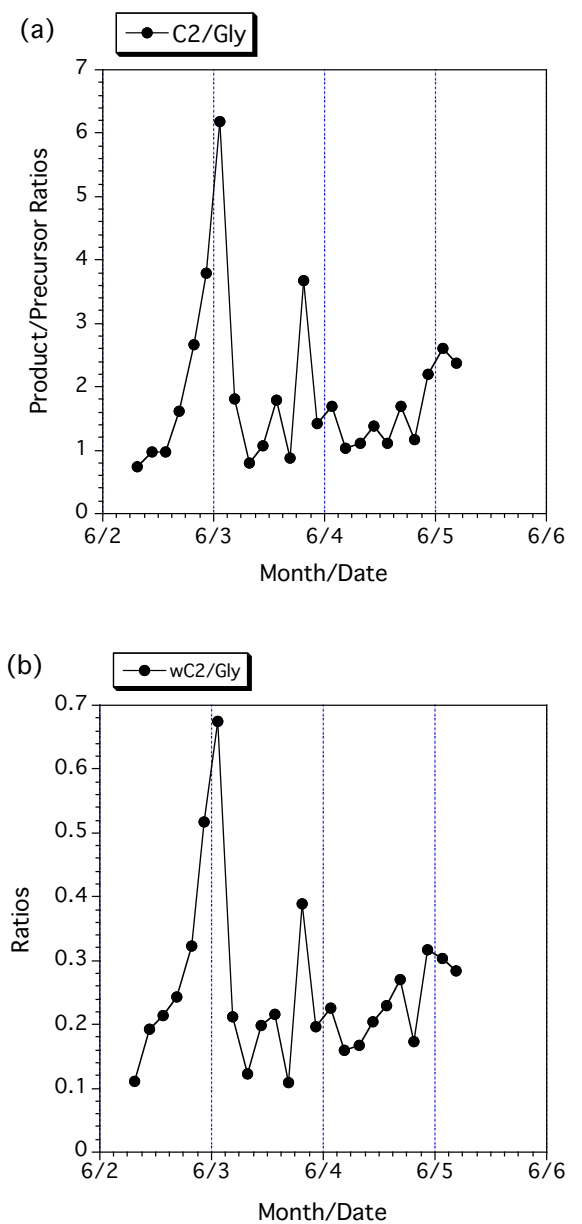

Fig. 12. Time-resolved variations in the concentration ratios of (a) particulate oxalic acid $\left(\mathrm{C}_{2}\right)$ /gaseous glyoxal (Gly) and (b) glyoxylic acid $\left(\omega \mathrm{C}_{2}\right)$ /gaseous Gly in the atmosphere of Mt. Tai. The data of organic acids in aerosols are from Kawamura et al. (2013).

oxalic acid in aerosols, suggesting a photochemical linkage between the carbonyls as precursors and oxalic acid as product. Further, the analyses of product/precursor ratios such as oxalic acid/glyoxal and glyoxylic acid/glyoxal showed an increase in the nighttime. These results suggested that oxalic acid and glyoxylic acid are produced by the aqueous phase oxidation of glyoxal in the aerosols in the upper troposphere during night when the ambient temperature decreases and relative humidity increases. This study emphasizes that bifunctional carbonyls are important atmospheric components that can act as precursors of secondary organic aerosols via heterogeneous reactions in aqueous aerosols during intensive field burning of agriculture wastes in the North China Plain.
Acknowledgements. This study was in part supported by the Japanese Ministry of Education, Culture, Sports, Science and Technology (MEXT) through grant-in-aid Nos. 17340166, 19204055 and 24221001 . We also acknowledge the financial support by the Global Environment Research Fund (B-051) of the Ministry of the Environment, Japan for the shipping of the instruments to Mt. Tai.

Edited by: S. C. Liu

\section{References}

Betterton, E. A. and Hoffmann, M. R.: Henry Law Constants of Some Environmentally Important Aldehydes, Environ. Sci. Technol., 22, 1415-1418, 1988.

Carlier, P., Hannachi, H., and Mouvier, G.: The Chemistry of Carbonyl-Compounds in the Atmosphere - a Review, Atmos. Environ., 20, 2079-2099, 1986.

Carlton, A. G., Turpin, B. J., Lim, H. J., Altieri, K. E., and Seitzinger, S.: Link between isoprene and secondary organic aerosol (SOA): Pyruvic acid oxidation yields low volatility organic acids in clouds, Geophys. Res. Lett., 33, L06822, doi:10.1029/2005GL025374, 2006.

Carlton, A. G., Turpin, B. J., Altieri, K. E., Seitzinger, S., Reff, A., Lim, H. J., and Ervens, B.: Atmospheric oxalic acid and SOA production from glyoxal: Results of aqueous photooxidation experiments, Atmos. Environ., 41, 7588-7602, 2007.

Carlton, A. G., Wiedinmyer, C., and Kroll, J. H.: A review of Secondary Organic Aerosol (SOA) formation from isoprene, Atmos. Chem. Phys., 9, 4987-5005, doi:10.5194/acp-9-4987-2009, 2009.

Christensen, C. S., Skov, H., Nielsen, T., and Lohse, C.: Temporal variation of carbonyl compound concentrations at a semi-rural site in Denmark, Atmos. Environ., 34, 287-296, 2000.

Dai, W. T., Ho, S. S. H., Ho, K. F., Liu, W. D., Cao, J. J., and Lee, S. C.: Seasonal and diurnal variations of mono- and di-carbonyls in Xi' an, China, Atmos. Res., 113, 102-112, 2012.

Ervens, B., Feingold, G., Frost, G. J., and Kreidenweis, S. M.: A modeling study of aqueous production of dicarboxylic acids: 1. Chemical pathways and speciated organic mass production, J. Geophys. Res.-Atmos., 109, D15205, doi:10.1029/2003jd004387, 2004.

Ervens, B., Carlton, A. G., Turpin, B. J., Altieri, K. E., Kreidenweis, S. M., and Feingold, G.: Secondary organic aerosol yields from cloud-processing of isoprene oxidation products, Geophys. Res. Lett., 35, GL031828, doi:10.1029/2007GL031828, 2008.

Ervens, B., Turpin, B. J., and Weber, R. J.: Secondary organic aerosol formation in cloud droplets and aqueous particles (aqSOA): a review of laboratory, field and model studies, Atmos. Chem. Phys., 11, 11069-11102, doi:10.5194/acp-1111069-2011, 2011.

Fu, P. Q., Kawamura, K., Okuzawa, K., Aggarwal, S. G., Wang, G., Kanaya, Y., and Wang, Z.: Organic molecular compositions and temporal variations of summertime mountain aerosols over Mt. Tai, North China Plain, J. Geophys. Res.-Atmos, 113, D19107, doi:10.1029/2008JD009900, 2008a.

Fu, T.-M., Jacob, D. J., Wittrock, F., Burrows, J. P., Vrekoussis, M., and Henze, D. K.: Global budgets of atmospheric glyoxal and methylglyoxal, and applications for formation of sec- 
ondary organic aerosols, J. Geophys. Res.-Atmos., 113, D15303, doi:10.1029/2007JD009505, 2008b.

Fu, T. M., Jacob, D. J., and Heald, C. L.: Aqueous-phase reactive uptake of dicarbonyls as a source of organic aerosol over eastern North America, Atmos. Environ., 43, 1814-1822, 2009.

Fu, P. Q., Kawamura, K., Chen, J., Li, J., Sun, Y. L., Liu, Y., Tachibana, E., Aggarwal, S. G., Okuzawa, K., Tanimoto, H., Kanaya, Y., and Wang, Z. F.: Diurnal variations of organic molecular tracers and stable carbon isotopic composition in atmospheric aerosols over Mt. Tai in the North China Plain: an influence of biomass burning, Atmos. Chem. Phys., 12, 8359-8375, doi:10.5194/acp-12-8359-2012, 2012.

Grosjean, D., Grosjean, E., and Moreira, L. F. R.: Speciated ambient carbonyls in Rio de Janeiro, Brazil, Environ. Sci. Technol., 36, 1389-1395, 2002.

He, N. and Kawamura, K.: Distributions and diurnal changes of low molecular weight organic acids and $\alpha$-dicarbonyls in suburban aerosols collected at Mangshan, North China, Geochemical Journal, 44, E17-E22, 2010.

Ho, K. F., Cao, J. J., Lee, S. C., Kawamura, K., Zhang, R. J., Chow, J. C., and Watson, J. G.: Dicarboxylic acids, ketocarboxylic acids, and dicarbonyls in the urban atmosphere of China, J. Geophys. Res.-Atmos., 112, D22s27, doi:10.1029/2006jd008011, 2007.

Ieda, T., Kitamori, Y., Mochida, M., Hirata, R., Hirano, T., Inukai, K., Fujinuma, Y., and Kawamura, K.: Diurnal variations and vertical gradients of biogenic volatile and semi-volatile organic compounds at the Tomakomai larch forest station in Japan, Tellus B, 58, 177-186, 2006.

Inomata, S., Tanimoto, H., Kameyama, S., Tsunogai, U., Irie, H., Kanaya, Y., and Wang, Z.: Technical Note: Determination of formaldehyde mixing ratios in air with PTR-MS: laboratory experiments and field measurements, Atmos. Chem. Phys., 8, 273 284, doi:10.5194/acp-8-273-2008, 2008.

Irie, H., Kanaya, Y., Akimoto, H., Tanimoto, H., Wang, Z., Gleason, J. F., and Bucsela, E. J.: Validation of OMI tropospheric $\mathrm{NO}_{2}$ column data using MAX-DOAS measurements deep inside the North China Plain in June 2006: Mount Tai Experiment 2006, Atmos. Chem. Phys., 8, 6577-6586, doi:10.5194/acp-8-6577-2008, 2008.

Kanaya, Y., Akimoto, H., Wang, Z.-F., Pochanart, P., Kawamura, K., Liu, Y., Li, J., Komazaki, Y., Irie, H., Pan, X.-L., Taketani, F., Yamaji, K., Tanimoto, H., Inomata, S., Kato, S., Suthawaree, J., Okuzawa, K., Wang, G., Aggarwal, S. G., Fu, P. Q., Wang, T., Gao, J., Wang, Y., and Zhuang, G.: Overview of the Mount Tai Experiment (MTX2006) in Central East China in June 2006: studies of significant regional air pollution, Atmos. Chem. Phys. Discuss., 13, 1527-1573, doi:10.5194/acpd13-1527-2013, 2013.

Kawamura, K. and Kaplan, I. R.: Motor-exhaust emissions as a primary source for dicarboxylic acids in Los Angeles ambient air, Environ. Sci. Technol., 21, 105-110, 1987.

Kawamura, K. and Ikushima, K.: Seasonal changes in the distribution of dicarboxylic acids in the urban atmosphere, Environ. Sci. Technol., 27, 2227-2235, 1993.

Kawamura, K. and Usukura, K.: Distributions of low molecular weight dicarboxylic acids in the North Pacific aerosol samples, J. Oceanogr., 49, 271-283, 1993.
Kawamura, K. and Yasui, O.: Diurnal changes in the distribution of dicarboxylic acids, ketocarboxylic acids and dicarbonyls in the urban Tokyo atmosphere, Atmos. Environ., 39, 1945-1960, 2005.

Kawamura, K., Kasukabe, H., and Barrie, L. A.: Source and reaction pathways of dicarboxylic acids, ketoacids and dicarbonyls in arctic aerosols: One year of observations, Atmos. Environ., 30, 1709-1722, 1996.

Kawamura, K., Kasukabe, H., and Barrie, L. A.: Secondary formation of water-soluble organic acids and $\alpha$-dicarbonyls and their contributions to total carbon and water-soluble organic carbon: Photochemical aging of organic aerosols in the Arctic spring, J. Geophys. Res.-Atmos., 115, D21306, doi:10.1029/2010jd014299, 2010.

Kawamura, K., Tachibana, E., Okuzawa, K., Aggarwal, S. G., Kanaya, Y., and Wang, Z. F.: High abundances of water-soluble dicarboxylic acids, ketocarboxylic acids and $\alpha$-dicarbonyls in the mountain aerosols over the North China Plain during wheat burning season, Atmos. Chem. Phys. Discuss., 13, 3695-3734, doi:10.5194/acpd-13-3695-2013, 2013.

Kleindienst, T. E., Conver, T. S., McIver, C. D., and Edney, E. O.: Determination of secondary organic aerosol products from the photooxidation of toluene and their implications in ambient $\mathrm{PM}_{2.5}$, J. Atmos. Chem., 47, 79-100, 2004.

Kundu, S., Kawamura, K., Andreae, T. W., Hoffer, A., and Andreae, M. O.: Molecular distributions of dicarboxylic acids, ketocarboxylic acids and $\alpha$-dicarbonyls in biomass burning aerosols: implications for photochemical production and degradation in smoke layers, Atmos. Chem. Phys., 10, 2209-2225, doi:10.5194/acp-10-2209-2010, 2010.

Legrand, M. and de Angelis, M.: Light carboxylic acids in Greenland ice: A record of past forest fires and vegetation emissions from the boreal zone, J. Geophys. Res.-Atmos., 101, 4129-4145, 1996.

Legrand, M., Preunkert, S., Oliveira, T., Pio, C. A., Hammer, S., Gelencser, A., Kasper-Giebl, A., and Laj, P.: Origin of C2-C5 dicarboxylic acids in the European atmosphere inferred from yearround aerosol study conducted at a west-east transect, J. Geophys. Res.-Atmos., 112, D23s07, doi:10.1029/2006jd008019, 2007.

Liggio, J., Li, S. M., and McLaren, R.: Heterogeneous reactions of glyoxal on particulate matter: Identification of acetals and sulfate esters, Environ. Sci. Technol., 39, 1532-1541, 2005.

Loeffler, K. W., Koehler, C. A., Paul, N. M., and De Haan, D. O.: Oligomer formation in evaporating aqueous glyoxal and methyl glyoxal solutions, Environ. Sci. Technol., 40, 6318-6323, 2006.

Matsunaga, S. and Kawamura, K.: Determination of $\alpha$ - and $\beta$ hydroxycarbonyls and dicarbonyls in snow and rain samples by GC/FID and GC/MS employing benzyl hydroxyl grime derivatization, Anal. Chem., 72, 4742-4746, 2000.

Matsunaga, S., Mochida, M., and Kawamura, K.: Variation on the atmospheric concentrations of biogenic carbonyl compounds and their removal processes in the northern forest at Moshiri, Hokkaido Island in Japan, J. Geophys. Res.-Atmos., 109, D04302, doi:10.1029/2003JD004100, 2004.

Miyazaki, Y., Aggarwal, S. G., Singh, K., Gupta, P. K., and Kawamura, K.: Dicarboxylic acids and water-soluble organic carbon in aerosols in New Delhi, India, in winter: Characteristics and formation processes, J. Geophys. Res.-Atmos., 114, D19206, 
doi:10.1029/2009jd011790, 2009.

Myriokefalitakis, S., Vrekoussis, M., Tsigaridis, K., Wittrock, F., Richter, A., Brühl, C., Volkamer, R., Burrows, J. P., and Kanakidou, M.: The influence of natural and anthropogenic secondary sources on the glyoxal global distribution, Atmos. Chem. Phys., 8, 4965-4981, doi:10.5194/acp-8-4965-2008, 2008.

Narukawa, M., Kawamura, K., Takeuchi, N., and Nakajima, T.: Distribution of dicarboxylic acids and carbon isotopic compositions in aerosols from 1997 Indonesian forest fires, Geophys. Res. Lett., 26, 3101-3104, 1999.

Okuzawa, K., Mochida, M., Bendle, J., Wang, H., and Kawamura, K.: Diurnal variation of semi-volatile dicarbonyls and hydroxycarbonyls in the urban atmosphere, Chikyukagaku (Geochemistry), 41, 125-134, 2007.

Ortiz, R., Hagino, H., Sekiguchi, K., Wang, Q. Y., and Sakamoto, K.: Ambient air measurements of six bifunctional carbonyls in a suburban area, Atmos. Res., 82, 709-718, 2006.

Possanzini, M., Tagliacozzo, G., and Cecinato, A.: Ambient levels and sources of lower carbonyls at Montelibretti, Rome (Italy), Water Air Soil Poll., 183, 447-454, 2007.

Ramanathan, V., Crutzen, P. J., Kiehl, J. T., and Rosenfeld, D.: Atmosphere - Aerosols, climate, and the hydrological cycle, Science, 294, 2119-2124, 2001.

Simoneit, B. R. T.: A review of biomarker compounds as source indicators and tracers for air pollution, Environ. Sci. Pollut. Res., 6, 159-169, 1999.
Smith, D. F., McIver, C. D., and Kleindienst, T. E.: Primary product distribution from the reaction of hydroxyl radicals with toluene at ppb NOX mixing ratios, J. Atmos. Chem., 30, 209-228, 1998.

Smith, D. F., Kleindienst, T. E., and McIver, C. D.: Primary product distributions from the reaction of $\mathrm{OH}$ with $\mathrm{m}-$, $\mathrm{p}$-xylene, 1,2,4- and 1,3,5-trimethylbenzene, J. Atmos. Chem., 34, 339364, 1999.

Spaulding, R. S., Schade, G. W., Goldstein, A. H., and Charles, M. J.: Characterization of secondary atmospheric photooxidation products: Evidence for biogenic and anthropogenic sources, J. Geophys. Res.-Atmos., 108, D4247, doi:10.1029/2002JD002478, 2003.

Volkamer, R., Martini, F. S., Molina, L. T., Salcedo, D., Jimenez, J. L., and Molina, M. J.: A missing sink for gas-phase glyoxal in Mexico City: Formation of secondary organic aerosol, Geophys. Res. Lett., 34, L19807, doi:10.1029/2007g1030752, 2007.

Warneck, P.: In-cloud chemistry opens pathway to the formation of oxalic acid in the marine atmosphere, Atmos. Environ., 37, 2423-2427, 2003.

Wittrock, F., Richter, A., Oetjen, H., Burrows, J. P., Kanakidou, M., Myriokefalitakis, S., Volkamer, R., Beirle, S., Platt, U., and Wagner, T.: Simultaneous global observations of glyoxal and formaldehyde from space, Geophys. Res. Lett., 33, L16804, doi:10.1029/2006GL026310, 2006. 